\title{
Selfies no Instagram: implicações de uma plataforma na configuração de um objeto de pesquisa
}

\author{
Sandra Portella Montardo' \\ https://orcid.org/0000-0001-8336-9329
}

I - FEEVALE

Novo Hamburgo (RS), Brasil

Resumo: Este artigo tem por objetivo identificar intervenções que a plataforma Instagram exerce em relação à configuração das selfies como objeto de pesquisa. Essa perspectiva se alinha com a abordagem que defende uma postura que visa tomar criticamente os dados digitais utilizados em investigações das Ciências Humanas e Sociais. Para tanto, em um primeiro momento, este artigo se vale do modelo proposto por Van Dijck (2013) que interpreta plataformas tanto como construtos tecno-culturais quanto como estruturas sócio-econômicas. A partir do tensionamento entre levantamento bibliográfico e evidências empíricas captadas em estudos anteriores, destaca-se que as dinâmicas incentivadas pela plataforma privilegiam a instantaneidade nas interações em torno de imagens, e levam a considerar as propriedades conversacionais das selfies para além de seu aspecto visual, em termos de legendas, hashtags e localização, reconfigurando a questão da visibilidade associada à exposição pessoal nesta plataforma.

Palavras-chave: selfies; plataforma; Instagram

Abstract: Selfies on Instagram: implications of a platform in the configuration of a research object. This paper aims to identify the interventions that the Instagram platform calls upon the configuration of selfies as a research object. This perspective aligns itself with the approach which defends a position that aims to consider critically digital data used in investigations of Social Sciences and Humanities. For this purpose, this article is based on the model posited by Van Dijck (2013), who interprets platforms both as techno-cultural constructs and socio-economic structures. From the confrontation between literature review and empirical evidences obtained in previous studies, it is highlighted that the dynamics encouraged by the platform come to consider selfies performativity beyond its visual aspect, in terms of captions, hashtags and location, reconfiguring the question of visibility associated with to personal exposure on that platform.

Keywords: selfies; platform; Instagram 


\section{Introdução}

Este artigo parte da premissa de Schäfer e Van Es (2017) segundo a qual é necessário desenvolver ferramentas conceituais por parte das Ciências Sociais Aplicadas e Humanidades para compreender a cultura contemporânea cada vez mais atravessada por componentes maquínicos e por processos automatizados. Nesse sentido, para os organizadores da coletânea The datafied society: studyind culture through data (2017), é fundamental entender como os dados digitais são gerados, coletados, selecionados e analisados, tendo-se em vista de que esses processos são incorporados no conhecimento produzido sobre a realidade que se pretende apreender a partir deles (WEINBERGER, 2014; MEYER; SCHROEDER, 2015). Ainda quanto a isso, concorda-se com Ramsey (2003), citado pelos autores da referida coletânea, quando este afirma que o uso de dados digitais na pesquisa social e de humanidades vai além da simples validação empírica ou teste de hipóteses, mas deve ser tomado para o desenvolvimento de questões e descoberta de insights.

Para fins de sistematização da exploração de selfies como "imagem autofotográfica compartilhada" (GUNTHERT, 2015a, p. 1), pergunta-se: quando se consideram selfies publicadas no Instagram, como esta plataforma intervém na sua constituição como objeto de pesquisa? Frente a isso, este artigo tem por objetivo identificar implicações que a plataforma Instagram exerce em relação aos elementos constitutivos da selfie.

Para dar conta desse objetivo, primeiramente, abordam-se questões conceituais relativas a plataformas digitais para, em seguida, examinar a plataforma Instagram à luz do modelo proposto por Van Dijck (2013). A autora (2013) combina a Teoria Ator-Rede e a Economia Política como meio de captar a sociabilidade projetada pelo que chama de mídias de conectividade, que não consistem em objetos acabados, uma vez que são afetadas continuamente por questões técnicas, sociais, econômicas, culturais e políticas, moldando, em contrapartida, essas mesmas questões. Por conta da complexidade desse cenário, Van Dijck (2013) examina Facebook, Twitter, Flickr, Youtube e a Wikipedia, a partir de um modelo que toma essas plataformas tanto como construtos tecno-culturais (tecnologia, conteúdo e usuários/usos) quanto como estruturas sócio-econômicas (propriedade, governança e modelo de negócios). Acredita-se que esse modelo é pertinente neste estudo uma vez que permite identificar aspectos culturais atrelados a sistemas automatizados nas selfies postadas no Instagram. Em seguida, uma seção examina o conceito de selfies e variações de abordagem dos seus elementos constitutivos no decorrer dos anos. Uma última seção é voltada para a descrição dos efeitos dessa plataforma no estudo das selfies na atualidade.

\section{Sobre plataformas digitais}

Uma vez que este estudo investiga de que forma o fato de selfies serem postadas no Instagram podem afetar a forma de explorá-las como objeto de pesquisa, torna-se 
pertinente examinar conceitos e abordagens referentes a plataformas digitais. Com isso, esta seção contextualiza o modelo proposto por Van Dijck (2013) a ser aplicado ao Instagram a seguir.

Para Gillespie (2010), citado por Van Dijck (2013), plataformas referem-se a: 1) conceitos computacionais e arquitetônicos; 2) planos de ação política e infraestruturas performativas. Alinhado com a Teoria Ator-Rede, Gillespie (2010) aponta que uma plataforma é antes um mediador, que transforma e interfere no curso da ação do que apenas um intermediário, que facilita ação.

\begin{abstract}
Tecnologicamente falando, plataforma são os provedores de software, (às vezes) hardware, e serviços que ajudam a codificar atividades sociais em uma arquitetura computacional; elas processam (meta)dados através de algoritmos e de protocolos formatados mediante apresentação de sua lógica traduzida na forma de interfaces amigáveis com configurações-padrão que refletem as escolhas estratégicas de seus proprietários (GILLESPIE, 2010 apud VAN DIJCK, 2013, p. 29).
\end{abstract}

De maneira mais enfática, Gillepsie (2015) afirma que plataformas importam no sentido em que, ao mesmo tempo que, tecnicamente, promovem algumas conexões entre indivíduos, impedem outras, privilegiando, também, de acordo com seu design técnico, imperativos econômicos e enquadramentos regulatórios, a circulação de algumas imagens e postagens em detrimento de outras. Essa condição, invariavelmente, afeta a participação na vida pública.

Ainda que reconheça as plataformas de redes sociais como instrumento importante na dinâmica de promoção de conexão como um valor social, Van Dijck (2013) pontua que mais do que apenas facilitar trocas entre os usuários ou viabilizar sua participação em torno de algum interesse comum, as plataformas configuram-se como "sistemas automatizados que projetam e manipulam conexões" (VAN DIJCK, 2013, p. 12). Em outras palavras, a fim de identificar gostos e preferências das pessoas, as plataformas codificam relações entre pessoas, coisas e ideias em algoritmos. Percebe-se, então, que as plataformas contemplam tanto a conexão humana quanto a conectividade automatizada, ainda que os discursos dos CEOs dessas plataformas tendem a enfatizar apenas o primeiro aspecto.

Quanto a isso, é válido referir o conceito de sociabilidade programada proposto por Bucher (2012). A partir dos Estudos de Software, Bucher (2012) investigou os modos através dos quais softwares moldam a sociabilidade em sites de redes sociais via estudos de caso do Facebook e do Twitter. Frente a isso, sociabilidade programada designa a condição segundo a qual os sites de redes sociais moldam a sociabilidade por meio de algoritmos ao incentivar a participação dos usuários nesses espaços (BUCHER, 2012). A partir de uma perspectiva foucaultiana, a autora (2012) conclui que os algoritmos impõem condições específicas de estar junto online, de modo que a atenção dos usuários é direcionada para a interação o que, por sua vez, permite que as plataformas monetizem 
os dados daí resultantes sob forma de publicidade personalizada, por exemplo. No caso do Facebook, Van Dijck (2013) identifica que o sistema encoraja que as pessoas conectem-se umas com as outras, conhecidas ou não, incentivando-as a estabelecerem interações dentro da plataforma via troca de conteúdo pessoal ou informativo, ações promovidas por recursos automáticos (curtir, compartilhar, reações etc.) em que identifica uma ideologia do compartilhamento que, por sua vez, leva à exposição desses usuários na plataforma.

Deve-se ressaltar que o conhecimento detalhado de gostos e preferências dos usuários, codificado em dados a partir das interações geradas nesses espaços, ocasiona a criação de ferramentas que, ao dirigir esses aspectos, vai, inevitavelmente, afetá-los. Nesse sentido, Van Dijck (2013) destaca que a conectividade passa a ser um valor quantificável e, por isso, manipulável, tanto pelas plataformas, quanto por agentes humanos e não-humanos. Trata-se do princípio da popularidade que, no contexto das plataformas, é tomado apenas por um viés quantitativo, indicando aprovação ou desaprovação, por exemplo, convertendo-se, com isso, em influência, autoridade e reputação.

Nesse sentido, ao explorar narrativas sobre o feed de notícias do Facebook, Araújo (2017) recorre a Beer (2016) para referir o imperativo de visibilidade. De acordo com Beer (2016), para ser alimentada, a imensa base de dados de plataformas como o Facebook depende da atuação dos usuários na plataforma, sob a forma de interações. Portanto, em consonância com os interesses das plataformas, a noção de visibilidade converte-se em valor positivo, incentivando a exposição pessoal, o que leva a uma redefinição da questão da privacidade.

Como se sabe, visibilidade ou exposição pessoais na contemporaneidade não se restringem à socialização online. Sennett (1998) descreve o processo de dissolução dos limites entre espaços público e privado na modernidade, que culmina com a organização da experiência pelo indivíduo para posterior submissão ao espaço público. Taylor (2011) associa a cultura do narcisismo a um desejo individual de autorrealização, independente de demandas que ultrapassam o indivíduo, o que o torna impotente em relação ao poder público. Ehrenberg (2010), por sua vez, associa o esfacelamento do Estado-providência, e o cenário de instabilidade decorrente disso com a emergência de uma pressão no sentido de que o indivíduo se torne empreendedor de si. Frente a isso, o autor (2010) destaca a relação inédita entre a identidade pessoal e a visibilidade social, e entre esta e a autenticidade. Dessa forma, ao invés de depender de pertencimentos coletivos tradicionais, a construção de identidade passaria a estar vinculada a um projeto voltado ao futuro, por intermédio de uma performance individual.

Inúmeros estudos levam em conta aspectos dessas perspectivas para investigar a exposição pessoal mediada por plataformas digitais, como blogs (SIBILIA, 2003), inclusive analisando-se as selfies nesse contexto (GALINDO, 2014), sem, no entanto, aprofundarem aspectos relativos às plataformas consideradas.

Para fins de exploração do Instagram, no sentido de mapear possíveis intervenções desta plataforma na constituição do objeto de pesquisa (selfies), a próxima seção aplicará 
o modelo analítico proposto por Van Dijck (2013) a essa plataforma. Conforme já foi posto, para a autora (2013) plataformas podem ser compreendidas tanto como construtos tecnoculturais (tecnologia, conteúdo e usuários/usos) quanto como estruturas sócio-econômicas (propriedade, governança e modelo de negócios) desde que se sobreponha esses elementos e camadas entre si. Cada elemento constitutivo desse modelo será definido na próxima seção, na medida em que forem identificados no processo de exploração do Instagram enquanto plataforma digital.

\section{Instagram como plataforma: imperativo da instantaneidade}

Conforme já foi posto, o corpus desse projeto se resume a selfies postadas na plataforma Instagram por este ter sido o primeiro site de rede social nativo mobile, ou seja, projetado para rodar em dispositivos móveis, aspecto fundamental para a facilidade na captura e compartilhamento desse tipo de imagem (MONTARDO et. al., 2017a). No entanto, atualmente, a plataforma pode ser utilizada, ainda que parcialmente, também em desktops e notebooks.

O Instagram é um aplicativo de rede social lançado em 2010 por Kevin Systrom e por Mike Krieger que permite o compartilhamento de fotografias e vídeos e a interação entre seus usuários por meio de comentários e de atribuição de likes. Seu nome surge a partir da combinação de duas palavras e conceitos que essencialmente formam a rede: o "insta" (instant) tem sua origem na inspiração vinda das câmeras de impressão instantânea, como a Polaroid, e confere a atmosfera vintage que os empresários queriam dar ao app (o que se confirma por meio dos filtros possíveis de serem aplicados às fotos e do logo inicial, por exemplo); já o "gram" (telegram) compara compartilhamento e telegrama (VILICIC, 2015). O aplicativo é composto por perfil (informações básicas, número de seguidores, publicações realizadas), feed ou timeline (mostra publicação de contas seguidas), seção explorar (mosaico personalizado de fotografias, vídeos e histórias mais populares), seção atividade (registro de interações do usuário e das pessoas que seguem), histórias (fotografias e vídeos disponíveis por 24 horas), Instagram Direct (mensagens instantâneas privadas entre os usuários) e filtros e ferramentas de edição das fotos (FANTONI, 2017). Em outubro de 2017, o Instagram possuía 800 milhões de contas ativas em todo mundo, sendo que 50 milhões de usuários ativos por mês eram brasileiros¹, a segunda maior base de usuários da plataforma. Em junho de 2018, o Instagram atingiu 1 bilhão de usuários².

Desde o seu surgimento, o aplicativo passou por inúmeras mudanças, que aumentaram consideravelmente a partir de 2012, ano em que o Instagram foi vendido para o Facebook, por 1 bilhão de dólares (VILICIC, 2015). Entre as principais atualizações,

1 Disponível em: <http://www1.perfil folha.uol.com.br/mercado/2017/10/1931057-com-50-milhoes-de-usuariosbrasil-e-segundo-no-ranking-do-instagram.shtml>. Acesso em: 11 fev. 2018.

2 Disponível em:<https://canaltech.com.br/redes-sociais/instagram-bate-marca-de-1-bilhao-de-usuariosativos-116344/. Acesso em: 31 ago. 2018. 
destacam-se: 1) possibilidade de postagem de vídeos de 15 segundos (atualmente, eles podem ter até 60 segundos) além de fotos em 2013; 2) Instagram Direct em 2013; 3) veiculação de publicidade, anunciada em 2013, e efetivada, no Brasil, em 2015; 4) alterações na ordem de apresentação de postagens no feed de notícias, privilegiando, não mais a ordem cronológica inversa, mas o histórico de interações entre os usuários envolvidos, em 2016; 5) mudança do logotipo em 2016; 6) disponibilização do recurso Histórias, em agosto de 2016, que permite que fotos e vídeos sejam dispostos em formatos de slides por apenas 24 horas. (FANTONI, 2017).

Essa breve descrição de funcionamento e atualizações do Instagram revela a interoperabilidade de aspectos relativos à plataforma entre sua dimensão 1) tecnocultural (tecnologia, usuários/usos e conteúdo) e a de 2) estrutura econômica (propriedade, governança e modelo de negócios) (VAN DIJCK, 2013). Quanto a isso, percebe-se que atualizações referentes à tecnologia, que dizem respeito a softwares e serviços, entendidos em termos de (meta)dados, algoritmos, protocolos e interfaces, responsáveis por converter, mediante certas condições, atividades sociais em dados, estão intrinsecamente associadas a questões de propriedade (relação entre grandes corporações e startups, mediante compra ou partilha de base de dados) e de modelo de negócios (formas de monetizar as plataformas, via venda de assinaturas, download pago de certos produtos e publicidade) (Van Dijck, 2013). Nesse sentido, observa-se, claramente, o aumento do ciclo de atualizações do Instagram, bem como o direcionamento de novas funcionalidades, a partir de sua venda para o Facebook (2012). Destaca-se, quanto a isso, a possibilidade de inclusão de vídeos na plataforma e do Instagram Direct, em 2013. Percebe-se nessas atualizações o interesse da plataforma na promoção de interação entre seus usuários por meio de conteúdo audiovisual (VAN DIJCK, 2013, BUCHER, 2012), o que permite a geração de dados baseados nesse comportamento. A consequência previsível dessa situação, em termos de modelos de negócio, é a venda de publicidade no Instagram, nesse mesmo ano, que vem atrelada à alteração da forma de exposição das postagens dos seguidores, reforçando a lógica da visibilidade conforme Beer (2016).

Sem dúvida, a mudança mais significativa do Instagram foi o acréscimo do recurso Histórias (conteúdo), em agosto de 2016, que pode ser interpretado como uma reação à recusa de venda do Snapchat, ferramenta que popularizou compartilhamento de vídeos instantâneos (disponíveis apenas por 24h) e os filtros aplicáveis a eles, ao Facebook em 2013. A mídia especializada atribui o crescimento das Histórias do Instagram (700 milhões de usuários) aliada à queda de usuários do Snapchat (250 milhões de usuários) $^{3}$, nesse período, devido, principalmente, à familiaridade de uso de sua interface por parte dos instagrammers (tecnologia, uso/usuários), aproveitamento da base de usuários (uso/usuários, modelo de negócios) e, principalmente, pelo fato de que a construção

3 Disponível em: <https://brasil.elpais.com/brasil/2017/08/02/tecnologia/1501658806_683191.html>. Acesso em 13 fev. 2018. 
de visibilidade no Snapchat, interesse de influenciadores digitais, dependesse de outras plataformas $^{4}$ (tecnologia). Em junho de 2018, o número de usuários do Snapchat baixou ainda mais, contando com 191 milhões de usuários ${ }^{5}$.

De acordo com Van Dijck (2013), o conteúdo (fotos, vídeos, texto e música etc.) vem sendo negligenciado nos estudos de mídias sociais, embora seja fundamental para agregar grupos em uma plataforma e indicar tendências e preferências de consumo. Em termos de tecnologia, a autora (2013) faz notar que as plataformas recorrem a padrões simplificados em suas interfaces para facilitar o seu manejo por parte dos usuários (encontrar, postar, compartilhar conteúdos) e promover a conexão entre eles. No caso do Instagram, chama a atenção não só o interesse da plataforma em motivar interações por meio do conteúdo audiovisual (fotos e vídeos), mas também em viabilizar a instantaneidade nesse ato. O fato de o conteúdo, seja ele foto ou vídeo, desaparecer em 24 horas, no recurso Histórias, pode ser entendido como uma estratégia da plataforma de fazer o usuário ser constantemente ativo no sentido de produzir e disponibilizar conteúdos pessoais. Além disso, o prefixo "Insta" na marca Instagram remetia à instantaneidade do ato de se publicar, em 2010, apenas fotos. Porém, a existência de recursos de edição e filtros para a manipulação de imagens na própria plataforma, associada com aplicativos externos de monitoramento de perfis, que indicam horários mais propícios para se realizar uma postagem com a finalidade de atingir mais visibilidade (curtidas e comentários), parece contradizer essa questão ao menos quando se considera um público jovem ${ }^{6}$, como nos mostra Fantoni (2017).

Com ênfase no aspecto propriedade (VAN DIJCK, 2013), cabe destacar que o Facebook parece reservar seu imperativo do compartilhamento (VAN DIJCK, 2013) apenas para si mesmo, ainda que um usuário possa compartilhar sua foto ou vídeo postados no Instagram com facilidade no Facebook. Recursos como "repost" são possíveis apenas pelo uso de aplicativos externos à plataforma, o que parece confirmar o foco da plataforma em instantaneidade.

Em estudo sobre os usos do Instagram, Manovich (2016) menciona a revolução do "instant", que pode ser traduzido tanto como instante e como instantâneo. A partir da análise de 15 milhões de imagens compartilhadas na plataforma, entre 2012 e 2015, em 16 cidades globais, o autor (2016) identificou que a maioria das fotos mostrava momentos triviais a serem compartilhados com amigos, familiares e conhecidos. Uma característica desse tipo de imagem casual é não ter uma preocupação estética evidente, diferente das fotos profissionais ou de design, examinadas posteriormente pelo autor (2016). Ainda nesse sentido, vale lembrar estudo de Wu et al. (2014), a partir dos usos

4 Disponível em: <https://techcrunch.com/2017/01/30/attack-of-the-clone/>. Acesso em 13 fev. 2018.

5 Disponível em: <https://canaltech.com.br/redes-sociais/instagram-bate-marca-de-1-bilhao-de-usuariosativos-116344/>. Acesso em 31 ago. 2018.

6 Fantoni (2017) aplicou questionário sobre usos de Instagram com adolescentes entre 15 e 18 anos, que cursavam o Ensino Médio em escolas públicas e privadas de Porto Alegre, obtendo 53 respostas válidas. A partir dessa amostra, a autora selecionou 6 adolescentes ( 3 meninas e 3 meninos) que faziam usos distintos do Instagram para realização de entrevistas em profundidade. 
de 40 mil usuários de 179 países, que destaca selfies como o tipo de foto mais postado no Instagram entre 8 tipos identificados (selfies, amigos, moda, comida, gadgets, atividades, animais de estimação e fotos com texto).

A seção seguinte retoma alguns pontos aqui considerados no sentido de identificar traços das selfies que se evidenciam como seus aspectos constitutivos, em parte, pelo fato de terem sido postadas no Instagram.

\section{Conceito de selfies e variação na abordagem de seus elementos constitutivos}

Entender o Instagram como plataforma permite concluir que a investigação das selfies como fenômeno cultural atravessado por questões técnicas deve contemplar a condição conversacional aí compreendida, incluindo em sua análise a interferência de aspectos automatizados previstos na plataforma, além da maneira como os autores desse tipo de imagem fazem usos desses recursos.

Gunthert (2015a), que entende as selfies como sintoma de uma cultura conectada, atribui sua popularização a uma série de controvérsias midiáticas a seu respeito, em geral, associada à noção de pânico moral. Nesse intuito, o autor (2015a) acompanha o fenômeno desde o seu surgimento, no ano 2000, no Japão, devido, em parte, à popularização de câmeras digitais com recurso para fotos frontais, passando pela sua denominação como selfie, em 2002, na Austrália, até que se tornasse palavra do ano, pelo Oxford English Dictionary, em 2013. Com isso, o autor (2015b) flagra a consagração das selfies como uma das mais representativas expressões visuais contemporâneas desde sua condição de subcultura até se tornar mainstream, levando em conta as suas propriedades conversacionais.

Consta que o primeiro registro da palavra selfie foi feito no site australiano ABC Online, em 13 de setembro de 2002, em uma postagem realizada por Nathan Hope (Hopey) no fórum de discussão do site para denominar a foto que a acompanhava. Já a escolha de selfie como palavra do ano pelo Oxford English Dictionary em 2013 deveuse a um aumento da ocorrência da palavra na web em $17.000 \%$ no período. Esse cálculo é feito por meio de um programa que coleta mensalmente cerca de 150 milhões de palavras em inglês utilizadas na web e que são avaliadas pelos editores do dicionário7. De acordo com este dicionário, selfie designa uma foto que alguém tira de si mesmo, normalmente com smartphone ou webcam, e que é compartilhada por meio de mídias sociais. ${ }^{8}$

No entanto, chama a atenção que a dimensão técnica das selfies, de maneira geral, foi, por um período, negligenciada em seu estudo. Em um levantamento do estado da arte sobre o tema, Montardo e Weber (2018) destacam que, quando questões técnicas são levadas em conta nesses estudos, o são por meio do componente imagético das selfies ou do ato de se autofotografar em si, em detrimento do seu aspecto compartilhável.

7 Disponível em: <https://blog.oxforddictionaries.com/press-releases/oxford-dictionaries-word-of-the-\%20year2013>. Acesso em 03 jun. 2018.

8 Tradução livre de: "A photograph that one has taken of oneself, typically one taken with a smartphone or webcam and shared via social media". 
Nesse sentido, Gómez Cruz e Thornham (2015) problematizam abordagens de selfies como imagem representacional, sejam tomadas em termos de documentação do "self", seja como afirmação de identidade, uma vez que tais perspectivas não levariam em conta a dimensão sociotécnica do fenômeno, que articula diversos elementos da comunicação digital mediada. A partir dessa abordagem sóciotécnica, os autores (2015) destacam a questão da performatividade inerente ao fenômeno.

Em perspectiva semelhante, Artieri et al. (2015) propõem que selfies sejam "fotos instantâneas pessoais que a) são criadas com a consciência de pertencerem a um gênero específico de autorretratos; b) que combinam uma dimensão textual e icônica; c) que são espalhadas nas redes sociais de indivíduos" (ARTIERE et al., 2015, p. 17). Os autores (2015) partem da abordagem de Goffman (1974) para compreender a prática das selfies em termos de efeitos de enquadramento dados, especificamente, a partir de dois fatores: a) a locação em que a foto foi tirada; b) as legendas e a hashtag que dispõem esse gênero de foto. O estudo de caso se deu por meio da coleta de selfies postadas no Instagram marcadas pela hashtag \#selfie.

Di Foggia (2015) aborda a antifiguratividade das selfies, indicando que o contexto no qual esse tipo de imagem é gerada importa mais do que seu aspecto figurativo, ou "qualidade da imagem com referência icônica a objetos e temas pertencentes ao mundo natural (seres, fenômenos, coisas)"(DI FOGGIA, 2015, p. 1). A partir de vários exemplos, o autor demonstra que o fato de marcar as fotos com hashtags em determinadas plataformas se sobrepõe ao que é de fato autorretratado, assumindo uma abordagem não-icônica do fenômeno.

Assim como Artieri et. al (2015) e Di Foggia (2015), percebemos a importância de se considerar, com atenção, as hashtags e a locação em que as fotos foram tiradas como elementos importantes para investigar as selfies ao descrever o processo de constituição do corpus da pesquisa (MONTARDO et al., 2017a). Nesse sentido, devido a restrições de coleta automatizada pelas políticas de uso do Instagram, procedeu-se por uma busca manual de selfies nessa plataforma, seguida do desenvolvimento de um programa para a análise desse corpus. De acordo com os objetivos do projeto, o corpus foi constituído por 1991 selfies, marcadas com 4430 hashtags únicas e localização de 39 pontos turísticos em 13 capitais do Brasil. Entre os pontos que chamam a atenção na amostra em questão destacam-se os seguintes: 1) número superior de hashtags em relação a selfies capturadas, 2) a busca pelas hashtags selecionadas neste estudo, que remetem a questões tecnológicas envolvidas no ato de se autofotografar e de compartilhar selfies (Ex: \#gopro, \#drone, \#selfiestick etc.) ampliou a abrangência geográfica do projeto para além do Brasil pelo fato de que a plataforma não permitia a busca combinada de localização e hashtag, o que inviabilizou a amostra para os fins a serem investigados.

Devido ao grau de interferência da plataforma Instagram nos rumos da pesquisa, optamos por submeter o corpus a uma segunda plataforma em estudo posterior (MONTARDO et al., 2017b). Escolhemos o Google Photos pelo fato de ser representante 
de outro grande player do mercado de Comunicação Digital e de suportar a análise de imagens propriamente ditas. Como resultados dessa análise, percebemos: 1) a geração de álbuns diferentes para fotos tiradas na mesma localidade; 2) falhas na identificação de algumas imagens e, novamente, 3) impossibilidade de sobreposição de hashtags e de localização.

Em consonância com essas abordagens, estudos posteriores revelaram a preocupação de se tomar as "selfies não apenas como um tipo de foto, mas como uma rede de mediadores e suas ações, conformando hábitos e experiências diversos"(PASTOR, 2017, p. 160). Nesse estudo, Pastor (2017) identifica um tipo de intimidade relacional e partilhada por intermédio de produção e compartilhamento de imagens de si. Em um artigo posterior, o mesmo autor (2018) interpreta a postagem de selfies no Facebook como fenômeno que consiste no entrelaçamento de relações materiais e discursivas, envolvendo intenções pessoais e algoritmos. Nesse último artigo, Pastor (2018) se vale da extensão do Google Chrome Show Facebook Computer Vision Tags para analisar as tags atribuídas pela plataforma para selfies associadas pelos usuários com uma localização específica, identificando algumas inconsistências entre as supostas intenções de registro dos usuários e a forma como estas selfies serão disponibilizadas nas redes desse usuário, conforme os algoritmos do Facebook.

Frente a esse conjunto de abordagens, percebe-se que, desde quando foram nomeadas enquanto selfies (2002), as propriedades conversacionais desse tipo de imagem são levadas em conta. Seja em um fórum de discussão ou em sites de redes sociais em geral, selfies são destinadas a serem compartilhadas (GUNTHERT, 2015; OXFORD ENGLISH DICTIONARY). O que se observa, no decorrer do tempo, por meio de estudos que foram produzidos, principalmente, a partir de 2015, é que esse aspecto de compartilhamento por meio de plataformas digitais deslocou o foco do estudo das imagens e do ato fotográfico envolvidos no fenômeno das selfies para as questões técnicas inerentes à sua distribuição nesses espaços. Com isso, nota-se uma ênfase crescente na análise dos elementos não-icônicos que compõem as selfies, como legendas, hashtags, localização e metatags nas investigações mais recentes. A próxima seção irá especificar os pontos em que a plataforma Instagram pode ter influenciado essa questão.

\section{Efeitos do Instagram na construção das selfies como objeto de pesquisa}

Em relação ao objetivo deste artigo, que foi identificar intervenções que a plataforma Instagram exerce em relação à configuração das selfies como objeto de pesquisa, verificaram-se três efeitos principais: 1) modificações na abordagem de selfies; 2) interferência da plataforma ao acesso de selfies nela postadas e, conseqüentemente, sobre sua análise; 3) configuração de visibilidade atrelada à instantaneidade. Esses três efeitos são dependentes da centralidade dos elementos não-icônicos constitutivos das selfies, conforme será posto a seguir. 
Quanto ao primeiro efeito, cabe destacar que, embora o aspecto compartilhável das selfies sempre tivesse configurado como elemento constitutivo do conceito de selfies, apenas recentemente tem recebido atenção de pesquisadores que se debruçam sobre o tema, uma vez que quase a totalidade das primeiras investigações nesse sentido focaramse em aspectos icônicos ou no ato de se autofotografar inerente ao fenômeno. Por outras palavras, de acordo com a brevíssima genealogia do termo, apresentada na seção anterior deste artigo, se a prática de selfie se evidencia como um novo tipo de imagem facilitada em sua captação pelas câmeras digitais frontais no ano de 2000 (GUNTHERT, 2015a), e que são denominadas pela primeira vez como selfies em um fórum de discussão em 2002, popularizando-se em 2013 (palavra do ano pelo Oxford English Dictionary), considerar o compartilhamento de selfies postadas no Instagram pressupõe, necessariamente, a análise de seus elementos não icônicos, como legendas, hashtags e localização. Ainda que já se tenha levado esses elementos em conta em estudos anteriores, não consta que tivesse havido discussão a respeito da importância da plataforma na emergência desses elementos ou, mesmo, que a configuração de compartilhamento das selfies assume determinadas características conforme a plataforma em que são distribuídas. Nesse sentido, percebese claramente que a plataforma digital que conforma um fenômeno cultural o afeta, fazendo emergir aspectos de seu conceito original sob condições específicas. Nesse caso, compartilhamento de selfies no Instagram assume, em conjunto com a imagem, a forma de legendas, hashtags e localização.

Em relação ao segundo efeito, antes de mais nada, deve-se destacar que o aumento significativo do número de usuários no Instagram e, com isso, da profusão de selfies postadas nela (WU et. al, 2014), faz aumentar o interesse de pesquisadores que investigam selfies e outros fenômenos nesta plataforma ${ }^{9}$. Além disso, o Instagram molda, em larga medida, as formas como se pode acessar selfies e, também, como se pode analisá-las, conforme demonstrou-se na tentativa de constituição do corpus da pesquisa (MONTARDO et al., 2017a).

Essa consideração confirma a perspectiva teórica que defende a importância da compreensão do processo de constituição e dos critérios de seleção e de análise dos dados digitais, uma vez que esses processos afetam o conhecimento produzido a partir deles (SCHÄFER, VAN ES, 2017; WEINBERGER, 2014; MEYER; SCHROEDER, 2015). Nesse sentido, percebeu-se que o cruzamento entre dados de localização e de hashtags é impossibilitado pela plataforma, assim como a coleta automatizada de selfies. Essa condição levou a uma descaracterização da amostra inicial pretendida pelo projeto, uma vez que, ou se considera a localização (selfies tiradas em pontos turísticos brasileiros), ou as hashtags associadas a elas. Ou seja, considerar hashtags pressupõe levar em conta selfies postadas em qualquer lugar do mundo.

9 O evento Instagram Conference 2018: Studying Instagram beyond selfies, realizado em $1^{\circ}$. de junho de 2018 na Middlesex University London, é outro fator que reforça a popularidade das selfies na plataforma. 
Frente a isso, torna-se fundamental levar em conta as dinâmicas que conformam a plataforma, compreendendo-a como construto tecno-cultural e como estrutura sócio-econômica. (VAN DIJCK, 2013). De acordo com essa perspectiva, compreendese que o Instagram estimula a instantaneidade nas interações via compartilhamento de imagens, atividade que gera dados por meio de protocolos pré-estabelecidos, padronizados porque são destinados a serem monetizados. Quanto a isso, importa destacar o imperativo da visibilidade (BEER, 2016) potencializado por meio desses elementos não icônicos no Instagram, o que também é visado por companhias externas à plataforma, mas compatíveis, como aplicativos geradores de hashtags $s^{10}$ ou de monitoramento de perfis pessoais ${ }^{11}$. Como insight decorrente da exploração desses dados nos moldes apresentados (RAMSEY, 2003), verifica-se aí uma nova configuração de visibilidade, que contempla a conversão de conexão humana em conectividade automatizada (VAN DIJCK, 2013) por meio de likes, curtidas, comentários, seguidores, encorajados pelo compartilhamento de selfies sob forma de todos os seus componentes constitutivos de modo a privilegiar a instantaneidade. Nesse sentido, percebe-se que a expressão técnica dessa visibilidade via selfies deve ser investigada em conformidade, não só com as características da plataforma que suporta essa intenção de exposição, mas também com as de um ecossistema digital mais amplo capitaneado por ela, aliando motivações dos usuários quanto a isso e recursos utilizados para tanto.

Sandra Portella Montardo é professora e pesquisadora no PPG em Processos e Manifestações Culturais, no PPG em Diversidade Cultural e Inclusão Social e no Mestrado Profissional em Indústria Criativa na Universidade Feevale. sandramontardo@feevale.br

\section{Referências}

ARAÚJO, W. F. As narrativas sobre os algoritmos do Facebook. Uma análise dos 10 anos do Feed de Notícias. Tese (Doutorado em Comunicação Social) - Faculdade de Bibilioteconomia e Comunicação. Universidade Federal do Rio Grande do Sul, 2017.

ARTIERI, G. B.; FARCI, M.; ZUROVAC, E.; OREFICE, M.The framing effect of selfies. Pictures beyond photography. In: \#selfie. Imag(in)ing the self in digital media. Book of abstracts. In: \#selfie: Imag(in) ing the Self in Digital Media, 2015.

BEER, D. Metric power. Londres: Palgrave Macmillan, 2016.

10 Disponível em: <http://www.techtudo.com.br/listas/noticia/2016/08/sete-apps-para-encontrar-melhores-hashtagspara-usar-no-instagram.html>. Acesso em: 13 fev. 2018.

11 Disponível em: <http://www.techtudo.com.br/listas/noticia/2016/10/dez-sites-e-aplicativos-para-medir-o-seusucesso-no-instagram.html>. Acesso em: 13 fev. 2018. 
BUCHER, T. Programmed sociality: a software studies perspective on social networking sites. [S.I.]: Universidade de Oslo, 2012.

DI FOGGIA, G. About the anti-figurativeness of \#selfie. In: \#selfie. Imag(in)ing the self in digital media. Book of abstracts. In: \#selfie: Imag(in)ing the Self in Digital Media, 2015.

EHRENBERG, A. O culto da performance: da aventura empreendedora à depressão nervosa. Org. e trad. BENDASSOLLI, Pedro F. Aparecida,São Paulo: Ideias \& Letras, 2010.

FANTONI, A Autorrepresentação de Adolescentes Porto-Alegrenses no Instagram. 2017. 175 f. Dissertação (Mestrado em Comunicação Social) - Faculdade de Comunicação Social, Pontifícia Universidade Católica do Rio Grande do Sul: Porto Alegre, 2017.

GALINDO, M. Do self ao selfie: o autorretrato digital e a subjetividade contemporânea. Dissertação (Mestrado em Comunicação). Programa de Pós-Graduação em Comunicação. Universidade Federal Fluminense. 2014.

GILLESPIE, T. Platforms intervene. Social Media+ Society, v. 1, n. 1, 2015.

GOFFMAN, E. Frame Analysis. An Essay on the ORganization of Experience. New York: Harper \& Row, 1974.

GÓMEZ-CRUZ, E.; THORNHAM, H. Selfies beyond self-representation: the (theoretical) $f(r)$ ictions of a practice. In: Journal of Aesthetics \& Culture, London, Vol. 7, 2015.

GUNTHERT, A. The selfie: disease and emblem of the connected image. In: \#selfie. Imag(in)ing the self in digital media. Book of abstracts. In: \#selfie: Imag(in)ing the Self in Digital Media, 2015a.

La consécration du selfie. Études photographiques, Paris, n. 32, jul. 2015 b.

MANOVICH, L. Instagram and Contemporary Image, 2016. Disponível em: <http://manovich. net/content/04-projects/148-instagram-and-contemporary-image/instagram_book_manovich.pdf>. Acesso em: 07 jun. 2018.

MEYER, E.; SCHROEDER, R. Knowledge Machines: Digital Transformations of the Science and Humanities. Cambridge, MA: The MIT Press, 2015.

MONTARDO, S.P.; WEBER, C. Panorama dos estudos sobre selfies. In: MONTARDO, S.P. (Org.). \#selfies: subjetividade e tecnologia. Porto Alegre: Sulina, 2018.

MONTARDO, S. P.; PELLANDA, E.; PASE, A.; VELHO, E. Estudando a cultura através de selfies: implicações do aspecto digital dos dados em sua análise. Revista Rizoma, Santa Cruz do Sul, v. 5, n. 2, p. 42-55. 2017 a.

MONTARDO, S. P.; PELLANDA, E.; PASE, A.; VELHO, E. Além da face: uma análise computacional das selfies. In: Seminário Internacional de Comunicação, 14., 2017b, Porto Alegre. Anais... Porto Alegre: PUC-RS, 2017b, p. 516-517.

PASTOR, L. Autofotografia e relato de si. Materialidades digitais e audiência algorítmica na prática do selfie. In: Encontro Anual da Compós, 27., 2018, Belo Horizonte. Anais...Belo Horizonte: PUCMinas, 2018. p. 1-19.

PASTOR, L. Prática do selfie. Experiência e intimidade no cotidiano fotográfico. Revista Contracampo, Niterói, v. 36, n. 4. p. 157-173, 2017.

RAMSAY, S. Toward an Algorithmic Criticism. Literary and Linguistic Computing. v.18, n. 2, p. 167-174, 2003. Oxford.

SCHÄFER, M. T. \& VAN ES, K. (Ed.) The datafied society. Studying Culture through data. Amsterdam: Amsterdam University Press, 2017. 
SENNETT, R. O declínio do homem público: as tiranias da intimidade. São Paulo: Companhia das Letras, 1998.

SIBILIA, P. Os diários íntimos na Internet e a crise na interioridade psicológica. In: LEMOS, A.; CUNHA, P. Olhares sobre a cibercultura. Porto Alegre: Sulina, 2003.

TAYLOR, C. A ética da autenticidade. São Paulo: É realizações, 2011.

VAN DIJCK, J. The culture of connectivity. A critical history of social media. New York: Oxford University Press, 2013.

VILICIC, F. O clique de um bilhão de dólares. Rio de Janeiro: Intrínseca, 2015.

WEINBERGER, D. Too big to know: Rethinking knowledge now that the facts aren't the facts, experts are everywhere, and the smartest person in the room is the room. New York: Basic Books, 2014.

WU, Y.; MANIKONDA, L.; KAMBHAMPATI, S. What we Instagram: a first analysis of Instagram photo content and user types. Proceedings of the Eighth International AAAI Conference on Weblogs and Social Media, pp. 595-598, 2014. Michigan. 